\title{
Analysis of the Role of Dispersion of Rural Settlements against Natural Hazards in South Khorasan Province
}

\author{
Ali Asghar Hodaei ${ }^{1} \mathbb{D}, \underline{\text { Vahid Feizi }}{ }^{2} \mathbb{D}$
}

\author{
Date of submission: 6 Feb. $2021 \quad$ Date of acceptance: 23 Aug. 2021
}

\begin{abstract}
INTRODUCTION: Identification of the settlements located in high-risk zones in terms of natural hazards is one of the first steps in risk management and development planning. This study aimed to identify villages exposed to earthquakes and floods in South Khorasan province.

METHODS: The present study used the Analytic Hierarchy Process method to evaluate the validity and reliability of measuring instruments through exploratory factor analysis. Since the value of the KMO index was 0.879 , the number of samples was sufficient for analysis. Moreover, the significance of the Bartlett test was less than $5 \%$ and Cronbach's alpha coefficient was obtained at 0.856 ; accordingly, the questionnaire was reliable.

FINDINGS: Based on the spatial analysis of the seismic vulnerability, 214 and 502 villages were in the zone of very high and high vulnerability, respectively. Moreover, the results of flood vulnerability showed that the southern and northwestern parts of South Khorasan province had the lowest vulnerability. The number of villages located in the very high vulnerable zone was very limited and included only seven villages of Chenesht, Kalateh Abbas, Takti Ti, Tangel Behdan, Ebru, Khankuk, and Ostan Siah, which are located in the east of the province.

CONCLUSION: Based on the integrated results of two hazards (i.e., earthquakes and floods), it is observed that 523 rural settlements are in a very high-risk zone, which accounts for $14.7 \%$ of the total settlements in the South Khorasan province, compared to the total rural settlements. Furthermore, the highest dispersion frequency of rural settlements is in the zone of moderate vulnerability. This zone with 1,344 settlements includes about $37.7 \%$ of the total settlements in the province
\end{abstract}

Original Article

Keywords: Earthquake; Flood; Rural Dispersion; Spatial Zoning; South Khorasan.

How to cite this article: Hodaei AA, Feizi V. Analysis of the Role of Dispersion of Rural Settlements against Natural Hazards in South Khorasan Province. Sci J Rescue Relief 2021; 13(3): 202-13.

\section{Introduction}

$\mathrm{N}$ umerous accidents and incidents annually cause very significant human and financial losses in the country. The extent of destruction caused by natural disasters, especially earthquakes and floods is so vast that can affect very large areas of the country (1). Natural hazards, such as floods and earthquakes, have always had devastating effects throughout history and in geographical areas, especially in rural areas. Natural disasters are often silent and potentially damaging. From 2006 to 2015, natural disasters caused 771,911 casualties and more than
\$7,161,171 million financial losses worldwide (2). In recent years, given the importance of natural disasters and the threat that can pose to human lives and development, initiatives have been launched by the international community to create a global consensus to deal with them. Among these, one can refer to the "Development of 10-15-year strategies", "allocating an International Day for Disaster Risk Reduction", "Global movements on various topics, such as school safety, hospital safety, and safe cities", "Global and regional conferences for natural disaster management, such as the 1994 Yokohama World Conference, Hugo World Conference

1- Assistant Professor, Iran Helal Applied Sciences and Higher Education Institute, Tehran, Iran

2- PhD in Climatology, University of Tehran, Tehran, Iran

Correspondence to: Vahid Feizi, Email: vahid.feizi62@gmail.com 
2005, and Sendai World Conference 2015", "The biennial global platform for disaster risk reduction in Geneva", and "Regional emergency and disaster ministerial meeting in five continents" (3). Every year, natural hazards cause extensive damage, especially in developing countries. The available evidence also indicates a steady increase in all types of natural crises in terms of severity and frequency (4) so that since the 1970s, the number of people affected and the amount of economic losses caused by natural phenomena has increased dramatically (5). Reducing the irreparable damage of natural disasters in Iran requires proper knowledge of the causes and solutions (6). The United Nations (UN) has designated the last decade of the $20^{\text {th }}$ century (1990-2000) as the International Decade for Natural Disaster Risk Reduction, as proposed by the General Assembly. Recommendations of global and national documents, such as Iran's general policies to reduce the effects of natural disasters approved by the Expediency Discernment Council are based on the integration of development plans with disaster plans and reducing the effects of natural disasters (7). According to the UN Strategic Plan for Disaster Reduction, all hazards have two main sources, namely natural hazards and hazards caused by technology (hazards caused by human activity) ( 8 ,9). Vulnerability is a situation in which human settlements or buildings are endangered due to their proximity to risk factors and the construction quality or both (10). The vulnerability of individuals and places is a complex phenomenon that has been developed throughout history between humans and the environment (10). The concept of vulnerability may be defined as the likelihood of harm to a community, structure, service, or geographic area that could be destroyed or damaged by a particular hazard (12). Vulnerability can encompass various elements; however, in simple terms, it indicates the possibility of creating a negative trend for a suitable current situation in the future (13). Due to the vast area of South Khorasan province, the distribution of settlements in this province is also scattered. Natural hazards in this province have caused a lot of human and financial losses in recent decades. Therefore, this study seeks to identify the risks and dispersion of rural settlements in different vulnerabilities. Many studies have been conducted in Iran and other parts of the world in this regard.

Omidvar et al. (2013) in their study entitled "Development of criteria for vulnerability of small towns to natural disasters, Case study: Gilan-eGharb" initially reviewed the studies conducted on the criteria of vulnerability of small towns to natural disasters based on documentary and library studies. Subsequently, they applied the opinions of experts using the Analytic Hierarchy Process (AHP) method and EXPERTCHOICT software. Furthermore, using statistical analysis, the importance ratio for different criteria and the weight ratio of vulnerable areas of Gilan-e-Gharb have been determined, and finally, the vulnerability map of the city has been prepared (14). In 2015, Ghadiri in a study entitled "Socioeconomic factors affecting the vulnerability of residential fabric in Tehran to earthquakes", investigated the role of social and economic factors affecting the vulnerability of Tehran to earthquakes and concluded that along with factors, such as instability of the physical fabric of the city, socio-economic factors had effects on the vulnerability of the residential fabric of Tehran. Accordingly, in order to reduce vulnerability, in addition to technical and engineering factors, socio-economic factors must also be seriously considered (15). Alavi et al. (2016) in their study entitled "Evaluation of urban fabric vulnerability rate to earthquake using ANP and GIS techniques (Case study: Semirom city)" initially identified the effective criteria in the vulnerability of urban fabrics to earthquakes. The results of this study revealed that among the effective criteria, population density, secondary roads, and distance from the fault, are the most important, and the distance from cultural centers and educational centers is the least important factor in the vulnerability of urban fabrics (16). Yari and Heidari Sarban (2016) in their study entitled "Evaluation of the role of development projects in reducing the vulnerability of villages to earthquakes (Case study: Varzeqan city)" have pointed out that the villages are more vulnerable to natural earthquake hazards due to the low quality of buildings, and having worn out fabrics, as well as unstable structures. However, the amount of damage in villages with a master plan, and especially in villages where new constructions are constructed using building approval certificates has been greatly reduced (17). 
Similarly, Amiri et al. (2018) conducted a study entitled "Prioritizing flooding under Maharloo watersheds in Fars province using morphometric parameters and VIKOR decision model" to spatially prioritize flooding under Maharloo watersheds using morphometric parameters and VIKOR decision model. In this regard, 13 morphometric parameters, including slope, drainage density, stream frequency, constant of channel maintenance, drainage texture, roughness number, circulatory ratio, compression ratio, roughness ratio, stream length, form ratio, elongation ratio, and shape ratio, as well as a climate parameter, including rainfall have been selected and studied; moreover, they used the AHP model to determine the weight of the parameters (18). In 2016, Nguyen et al. assessed the eco-environmental vulnerability of Thua Thien-Hue Province and its largest river system in order to protect and manage the environment. In this study, 16 variables were used, and the variables were evaluated using AHP and GIS, and finally, a vulnerability map was prepared. The results showed that high and very high vulnerable areas were located in medium and weak lands where economic and social activities have developed rapidly (2). In 2017, Araghian et al. applied fuzzy logic in the assessment and zoning of earthquake vulnerability potential in rural settlements of Tarom County. The results showed that about $45 \%$ of the area in the northern and eastern parts is in a zone with high and very high vulnerability, and $40 \%$ of the area is in very low and low vulnerability (19). In 2017, Tilahun and Tarun conducted a GIS-based landslide hazard evaluation and zonation in Jeldu District, Central Ethiopia. In this study, landslide hazard evaluation and zonation were performed by LHZ map. The results showed that $92 \%$ of past earthquakes occurred in high-risk or very hazardous areas, while $6 \%$ were in moderate areas and only $2 \%$ in hazardous areas. Furthermore, the specific hazardous areas can be used for regional planning and infrastructure development (20). In 2019, Xue et al. conducted a 10-year spatiotemporal analysis of ecological vulnerability and management in the Tarim River Basin (20062015).

The results of this study showed that at the end of this period, the average ecological vulnerability was severe in the river basin, and this situation adopted an upward trend so that a very high level of vulnerability was reached in 2013-15. In general, the ecological vulnerability has a topdown gradient from east to west; moreover, high and very high vulnerability in the east indicates more human involvement in this basin. Finally, a number of suggestions were made to improve the vulnerability in this basin (21). Iran is one of the countries exposed to natural disasters in the world due to its geographical location, climatic conditions, and geological situation. Moreover, the historical records of various disasters, such as floods, earthquakes, landslides, and land subsidence in its area indicate the possibility of recurrence in the future. According to published statistics, Iran is one of the 10 most disaster- and unexpected events-prone countries in the world (22). In general, in recent years, especially in recent decades, Iran witnessed major unexpected events, including earthquakes (Tabas, Rudbar, Manjil, Buin Zahra, Bam, and Zirkuh in Ghaenat, as well as recent earthquakes in Kermanshah, Kerman, East Azarbaijan, and Bushehr), devastating floods in different parts of the country (Golestan, Neka, Talesh, and Qom, as well as recent floods in Mazandaran, East Azarbaijan, and Ilam provinces), and numerous other accidents and incidents, such as slope instabilities, all kinds of landslides and land subsidence in different parts of the country that caused significant damages and losses in urban and rural areas.

It is worth mentioning that there is always the possibility of recurrence of events and risk-prone situations in rural areas are far worse than those in urban areas in Iran. The factors leading to the high vulnerability of the rural areas to natural disasters include organic rural texture affected by various factors of the natural, social, and economic environment and often without planning; construction based on local knowledge and use of conventional building materials in different geographical areas; lack of public attention to the principles of engineering, safety and security of rural fabric and housing against natural disasters; lack of necessary rules and regulations in construction; large number and dispersion of rural areas and centers; use of conventional and instable materials; and the worn out of many old physical tissues of the villages. Accordingly, significant damage has occurred in these areas, following the occurrence of different kinds of events, especially floods and earthquakes. For instance, the 
occurrence of recent earthquakes in Kermanshah province (Azgeleh-Sarpol-e-Zahab region; November 13, 2017, with a magnitude of 7.3 Richter), East Azerbaijan (Ahar-Varzeqan region; August 12, 2012, with a magnitude of 6.4 Richter), and Khorasan Razavi (Sefid Sang region; April 6, 2017, with a magnitude of 6.1 Richter) destroyed or severely damaged a large number of villages. Reducing the vulnerability of settlements to earthquakes will occur when earthquake safety is considered at all levels of planning (22). In the event of an earthquake or similar incident, rescue centers in the city are responsible for assisting the victims on time. Equipping the relief centers and distributing the facilities fairly and in accordance with the existing per capita and standards is one of the important management measures, which can be used to protect the urban system against accidents and reduce the human and financial harmful consequences of these accidents (23). South Khorasan province with specific geotectonic location and numerous major and minor faults has high seismic sensitivity. Furthermore, due to the specific climate of the area and the existing channels, floods occur in this province every few years, which cause a lot of damage, especially in rural settlements. Therefore, this study investigated the vulnerability of South Khorasan province to earthquakes and floods. This study aimed to evaluate the effect of dispersion of rural settlements in relation to the impact of earthquake and flood hazards. Moreover, it attempted to find out the dispersion of rural settlements regarding natural hazards, such as earthquakes and floods.

\section{The scope of the study}

South Khorasan with an area of 149838/45 square kilometers includes 11 cities, namely Birjand, Tabas, Boshruyeh, Darmian, Sarayan, Sarbisheh, Ferdows, Ghaenat, Khosf, Zirkuh, and Nehbandan that are located in the eastern part of the country. This area includes the whole of South Khorasan province, and Tabas with 55,656 square kilometers is the largest city, followed by Nehbandan with 24,489 square kilometers. On the other hand, Birjand with 3,958 square kilometers is the smallest city in this province. This province is located within 55-61 degrees longitude and 30-35 degrees latitude. South Khorasan province is located in the easternmost part of the country and borders Afghanistan to the east. The political border of this province with Afghanistan is about $331 \mathrm{~km}$, which is of special importance due to its proximity to this country, communication routes, and border markets. Figure 1 shows the location of South Khorasan province in the country divisions.

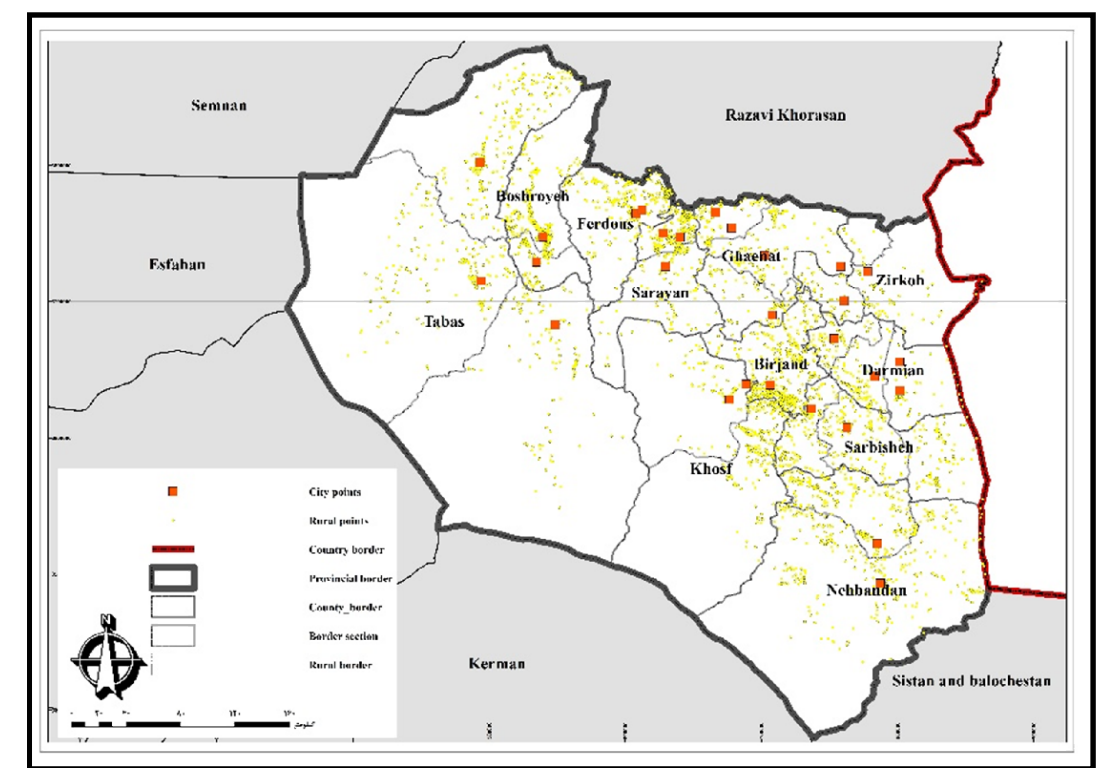

Figure 1. South Khorasan province location in the political country divisions 


\section{Methods}

The statistical population included all experts specialized in the field of study who were selected using the non-probability sampling method $(n=30)$. In the AHP method, initially, the validity and reliability of the measuring instrument were evaluated through exploratory factor analysis. To evaluate the model, the statistics related to the KMO index and Bartlett test statistics (it is an approximation of Chi-square test statistics) were initially measured. Since the KMO index value was 0.879 (close to one), the number of samples was sufficient for analysis, and this showed the efficiency of sampling. Moreover, the significance level of the Bartlett test was less than 5\%, which indicated that the matrix was not uniform, and factor analysis was appropriate to identify the structure. The questionnaire was reliable based on Cronbach's alpha coefficient of 0.856 , which was greater than 0.667 .

The AHP model consists of four main stages. The process of the hierarchical analysis model is as follows:

- Develop a hierarchical framework

- Determine the significance ratio of indicators and sub-indicators

To determine the significance ratio of indicators and sub-indicators, a pairwise comparison should be made based on a 1 to 9 numerical scale, as presented in Table 1.

- Determine the significant ratio of options After determining the significant ratio of the indicators and sub-indicators, the significant ratio of the options is determined using a 1 to 9 numerical scale, as presented in Table 2 (25).

- Develop overall option ranking

The significant ratios of the indicators and subindicators, as well as the options, have been determined so far in relation to the predetermined goal. At this stage, by combining the above significant ratios, the final rank of each option will be determined.

In the first step, in order to assess the vulnerability of floods and earthquakes, harmful or critical factors were identified. These factors have

Table 1. A 1 to 9 numerical scale for a pairwise comparison (24)

\begin{tabular}{|c|c|c|}
\hline Score & Description & Explanation \\
\hline 1 & Equal importance & In achieving the goal, two indicators are of equal \\
\hline 3 & Weak moderate importance & $\begin{array}{c}\text { Experience shows that } \mathrm{i} \text { is slightly more important than } \mathrm{j} \text { to } \\
\text { achieve the goal. }\end{array}$ \\
\hline 5 & Essential or strong importance & $\begin{array}{l}\text { Experience shows that } \mathrm{i} \text { is more important than } \mathrm{j} \text { to achieve } \\
\text { the goal. }\end{array}$ \\
\hline 7 & $\begin{array}{l}\text { Very strong or demonstrated } \\
\text { importance }\end{array}$ & $\begin{array}{l}\text { Experience shows that } \mathrm{i} \text { is much more important than } \mathrm{j} \text { to } \\
\text { achieve the goal. }\end{array}$ \\
\hline 9 & Absolute importance & The importance of $\mathrm{i}$ over $\mathrm{j}$ has definitely been proven. \\
\hline $2,4,6$ and 8 & $\begin{array}{l}\text { Intermediate values between two } \\
\text { adjacent scales }\end{array}$ & When there is an intermediate state. \\
\hline
\end{tabular}

Table 2. Number of recorded earthquakes in South Khorasan (1927 to 2019)

\begin{tabular}{|c|c|c|c|c|c|c|c|c|c|c|c|c|c|}
\hline \multirow[b]{2}{*}{ Richter } & \multicolumn{12}{|c|}{ Distribution of the number of occurred earthquakes } & \multirow[b]{2}{*}{ Relative share } \\
\hline & 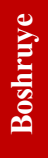 & 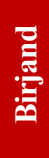 & 音 & 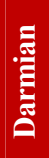 & 을 & 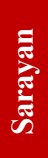 & 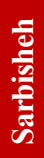 & $\frac{\mathscr{E}}{\tilde{E}}$ & 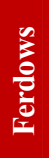 & 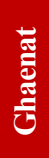 & 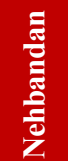 & Е & \\
\hline $2.5-3$ & 16 & 16 & 57 & 50 & 54 & 6 & 57 & 174 & 7 & 35 & 76 & 548 & 56.2 \\
\hline $3-3.5$ & 7 & 4 & 15 & 13 & 8 & 4 & 22 & 64 & 1 & 7 & 37 & 182 & 18.7 \\
\hline $3.5-4$ & 1 & 0 & 5 & 5 & 5 & 2 & 5 & 15 & 0 & 9 & 10 & 57 & 5.8 \\
\hline $4-4.5$ & 7 & 0 & 11 & 3 & 4 & 1 & 4 & 36 & 1 & 23 & 10 & 100 & 10.3 \\
\hline $4.5-5$ & 4 & 1 & 4 & 0 & 4 & 0 & 2 & 28 & 1 & 17 & 5 & 66 & 6.8 \\
\hline $5-5.5$ & 0 & 0 & 1 & 0 & 2 & 0 & 0 & 6 & 0 & 1 & 1 & 11 & 1.1 \\
\hline $5.5-6$ & 0 & 0 & 0 & 0 & 1 & 0 & 2 & 1 & 0 & 1 & 0 & 5 & 0.5 \\
\hline More than 6 & 0 & 0 & 0 & 0 & 1 & 0 & 0 & 1 & 0 & 4 & 0 & 6 & 0.6 \\
\hline Total & 35 & 21 & 93 & 71 & 79 & 13 & 92 & 325 & 10 & 97 & 139 & 975 & 100 \\
\hline
\end{tabular}


been identified using the Delphi method along with the opinion of experienced experts. South Khorasan province, the same as other parts of Iran, is almost completely damaged by several major factors, the most important of which are earthquakes and floods. An earthquake is the sudden release of a lot of energy in a very short period of time, which occurs due to turbulence in the earth's crust. The earthquake may release blocked energies (tens, hundreds, or thousands of years) in a second (26).

To identify high-risk areas in terms of seismicity, such criteria as fault, geology, soil science, land slope, land use, as well as land type have been studied. Flood as a phenomenon that causes economic losses and damages is of critical importance. In other words, flood is one of the most complex and destructive natural phenomena that endanger human life, property, as well as social and economic conditions of society more than any other natural disaster (27). To identify high-risk areas in terms of flooding, criteria, and information layers of rivers, land slope, slope direction, surface cover, land use, and soil science have been used in this study (28). In the second stage, after determining the critical factors, using the available reliable sources and the opinions of experienced experts regarding each critical factor, the criteria for each critical factor were determined. After determining the factors and criteria of each factor, each factor was evaluated, and each criterion was assessed according to the degree of impact on the critical factors. The evaluation stage of the factors and criteria was performed using the AHP model and Expert choice software (version 11); furthermore, a pairwise comparison was made for each criterion to identify the effectiveness of each criterion in the system, compared to the other criteria. In the next stage, the obtained value of each criterion was multiplied in a specific layer and using Arc GIS software (version10.3), the criteria of each factor were superimposed and the final output of each factor was obtained. Afterward, using the layer of rural points, the dispersion of each village was determined on the flood and earthquake hazard zones.

\section{Findings}

South Khorasan province with specific geotectonic location and numerous major and minor faults has high seismic sensitivity. A review of the history of earthquakes and recently recorded earthquakes indicates the occurrence of destructive and damaging earthquakes in recent periods; moreover, occasionally, one or more earthquakes have affected some of the settlements in the area. Table 2 summarizes the earthquakes recorded from 1973 to 2019.

According to the above Table, 975 earthquakes have occurred so far, of which about $56 \%$ had no high intensity and destructive effects. On the other hand, 22 earthquakes with a magnitude of more than 5 Richter were the most terrible in this province. Figure 2 shows the relative hazard zone of an earthquake and the location of the epicenter of the occurred earthquakes. As can be observed, there is a close relationship between important fault lines and the largest earthquakes in the province .

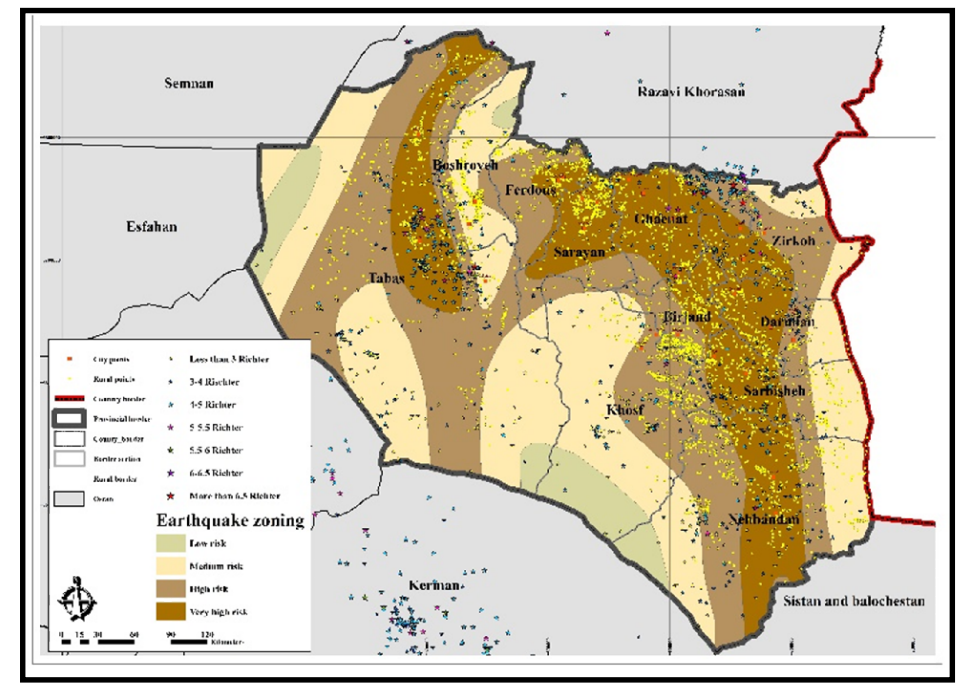

Figure 2. Zoning of the relative hazard of earthquakes and the location of occurred earthquakes 
In total, six parameters of fault, geology, soil science, slope, land use, and land type have been used to zone the earthquake vulnerability in the study area. According to the AHP method, the largest share among these parameters belonged to faults. The fault (0.338) and land type (0.085) factors obtained the most and least important in terms of creating an earthquake, respectively (Figure 3). After the fault layer, geology obtained the largest share in the seismic damage of the region. Figure 4 illustrates the seismic vulnerability zoning in South Khorasan province. According to this map, it can be noted that the range of fault expansion, especially overthrust fault and main faults are in the high-risk range. The frequent dispersion of these faults can be observed in the northwest and east of the province. Due to this range, the seismic risk is high in the northwestern and eastern parts of the province and is low in the southern parts of the province due to the type of faults; moreover, other areas are in the lower seismic risk range (Table 3). Furthermore, considering that one of the objectives of this study is to identify the villages of South Khorasan province in different vulnerability zones, a table of vulnerability zones has been extracted by

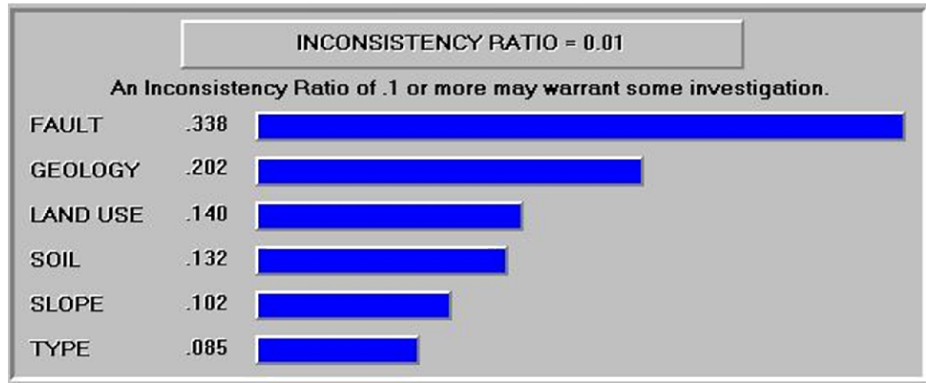

Figure 3. Two-by-two comparison of different parameters in creating an earthquake

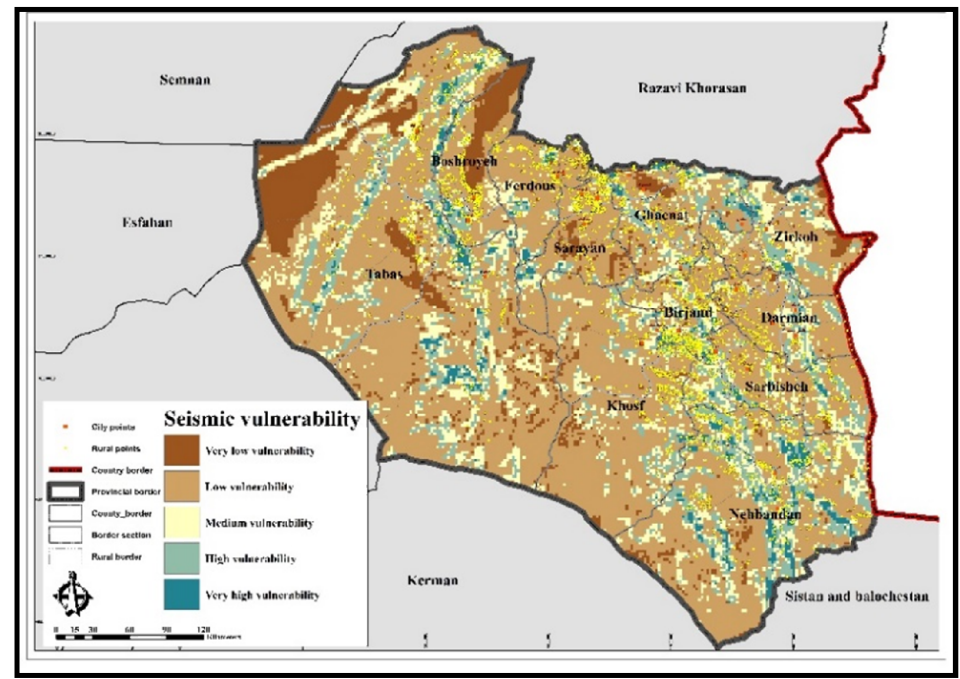

Figure 4. Seismic vulnerability zoning in South Khorasan province

Table 3. Dispersion of settlements in seismic vulnerability zones by city

\begin{tabular}{|c|c|c|c|c|c|c|c|c|c|c|c|c|}
\hline Vulnerability rate & 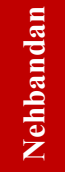 & 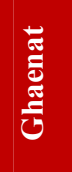 & $\frac{0}{0}$ & 总 & 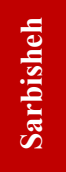 & 芶 & $\frac{\bar{E}}{\frac{0}{\vdots}}$ & 壱 & $\underline{\underline{z}}$ & 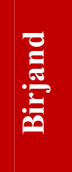 & 害 & 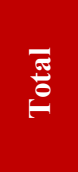 \\
\hline Very low vulnerability & 9 & 7 & 13 & 14 & 14 & 13 & 1 & 14 & 10 & 4 & 27 & 126 \\
\hline Low vulnerability & 223 & 163 & 198 & 288 & 183 & 226 & 61 & 146 & 206 & 179 & 257 & 2130 \\
\hline Medium vulnerability & 118 & 32 & 13 & 96 & 65 & 29 & 17 & 23 & 40 & 116 & 39 & 558 \\
\hline High vulnerability & 127 & 34 & 4 & 58 & 78 & 27 & 24 & 11 & 31 & 85 & 23 & 502 \\
\hline Very high vulnerability & 66 & 13 & 12 & 37 & 12 & 11 & 5 & 2 & 4 & 45 & 7 & 214 \\
\hline Total & 543 & 249 & 240 & 493 & 352 & 306 & 108 & 196 & 291 & 429 & 353 & 3560 \\
\hline
\end{tabular}


city and number of villages (Table 1).

According to Table 3, there are 3,560 villages in South Khorasan province. According to the seismic vulnerability zoning, the zone with the lowest vulnerability has the highest number of villages. This zone with 2,130 villages occupies about $60 \%$ of the villages. Tabas with 288 villages located in the low seismic vulnerability zone has the highest number of villages in this zone. Moreover, the zone with very low seismic vulnerability with 126 villages covers $63.37 \%$ of the total villages in the province, which have very low and low vulnerability. One of the important and significant points is the placement of 214 and 502 villages in the zones of very high and high vulnerability, respectively. Moreover, about $6 \%$ of the villages in the province are in a very high vulnerable zone. In addition, about $14 \%$ of rural settlements are in a highly vulnerable zone. In total, about $20 \%$ (onefifth) of the villages in South Khorasan province are in a highly vulnerable zone. Among the cities of the province, Nehbandan has the highest number of villages located in the zone of high and very high vulnerability due to the existence of many faults in this province. In total, about $55 \%$ of the villages in this city are in high and very high vulnerable zones.
Due to the fact that local materials are used in constructions in the villages, and the buildings are mostly constructed based on conventional methods, there is a high level of vulnerability to natural hazards. Therefore, government agencies, especially the Housing Foundation of the Islamic Revolution, should take necessary measures to rehabilitate endangered villages.

\section{Floods}

In order to zone the flood risk in the area under study, all steps described in the above discussions were taken, and the flood risk of the area was investigated using seven layers of the river, slope, slope direction, land type, geology, surface cover, and soil science. Moreover, Expert choice software was utilized to weigh each layer and sub-criteria (Figure 5). Finally, the vulnerability map of the area was obtained in terms of flooding. Based on this model, it is observed that rivers have the greatest impact on flooding in South Khorasan province. Furthermore, the parameter of the river $(0.36)$ obtains more than one-third of the risk of flooding, and soil science (0.06) has the lowest sensitivity. Figure 6 illustrates the flood

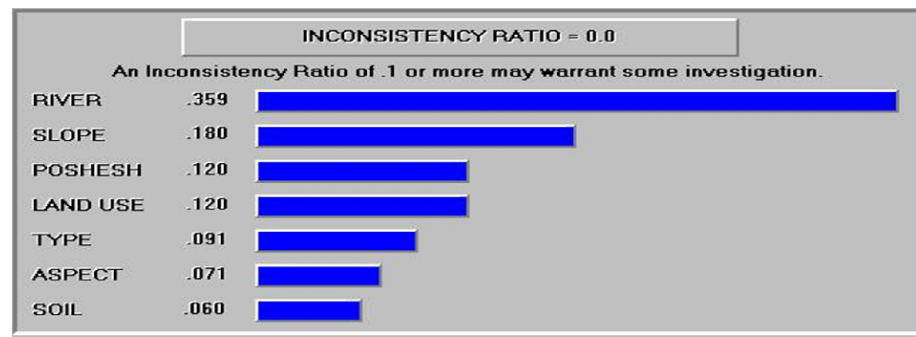

Figure 5. Two-by-two comparison of different parameters in flood occurrence

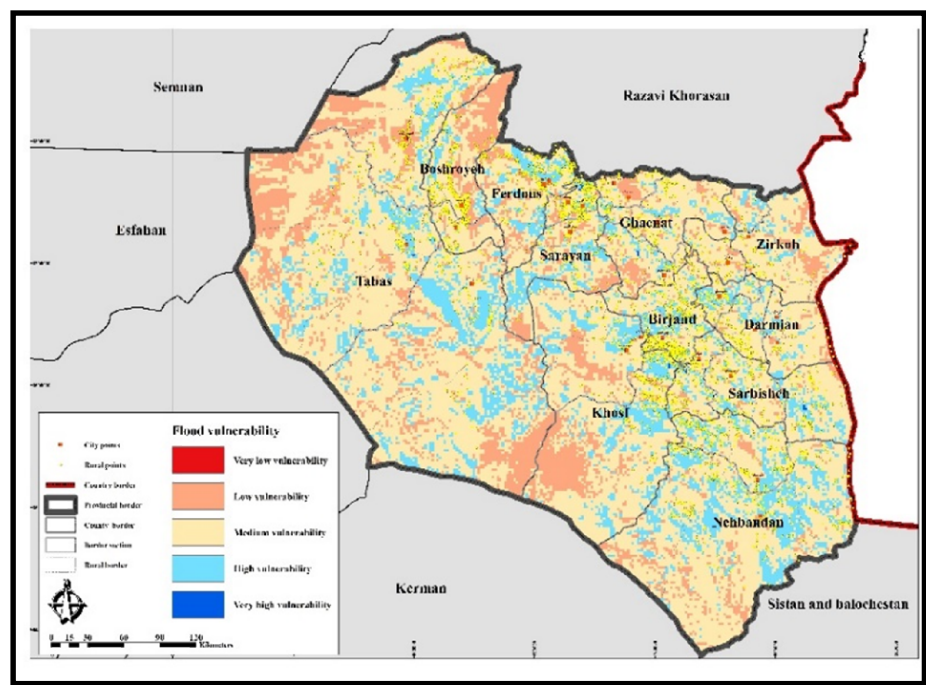

Figure 6. Flood vulnerability zoning in South Khorasan province 
vulnerability zoning in South Khorasan province. According to Figure 5, it can be noted that the middle, eastern, and southeastern parts are scattered and have a high degree of vulnerability around existing rivers and canals. Additionally, as we move from these areas to surroundings, there is less degree of flood vulnerability so that the southern and northwestern parts of Khorasan province have the lowest vulnerability to flooding. Based on the analysis of the spatial dispersion of rural settlements in South Khorasan province in flood vulnerability zones, it is observed that most of the villages in this province are in moderate vulnerability zones. This area covers about 2,489 (over $70 \%$ ) villages in the province. However, the number of villages located in the very vulnerable zone is very limited and includes only seven villages of Chenesht, Kalateh Abbas, Takti Ti, Tangel
Behdan, Ebru, Khankuk, and Ostan siah, which are located in the east of the province. There are 583 villages in the highly vulnerable zone, which accounts for $16 \%$ of the total villages in the province. Therefore, observing constructions in the river area, creating flood dams along the rivers, and using concrete walls are among the measures that can be taken to reduce the amount of flood damage (Table 4).

In order to obtain a clear interpretation regarding the integration of the two hazards under study, an integrated map of these two hazards was prepared. According to this map, it is observed that the eastern and western parts of the province have the highest level of vulnerability. Figure 7 shows the integrated vulnerability zoning of two hazards in South Khorasan province. Based on this map and the Table, 523 rural settlements are in a very high-risk zone, which is about $14.7 \%$ of

Table 4. Dispersion of settlements in flood vulnerability zones by city

\begin{tabular}{|c|c|c|c|c|c|c|c|c|c|c|c|c|}
\hline Vulnerability rate & 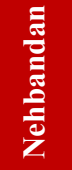 & 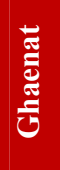 & 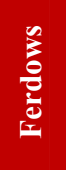 & $\frac{\mathscr{0}}{\frac{\mathscr{J}}{\sigma}}$ & 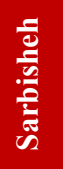 & 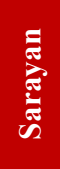 & $\frac{\bar{E}}{\bar{E}}$ & 离 & $\frac{\mathrm{z}}{\mathrm{E}}$ & 苞 & 递 & $\stackrel{\overline{5}}{\stackrel{5}{\theta}}$ \\
\hline Very low vulnerability & 7 & & 3 & & 3 & 1 & 1 & 6 & & & & 21 \\
\hline Low vulnerability & 11 & 17 & 50 & 99 & 17 & 35 & 22 & 9 & 28 & 33 & 139 & 460 \\
\hline Medium vulnerability & 365 & 209 & 149 & 325 & 291 & 217 & 81 & 146 & 186 & 318 & 202 & 2489 \\
\hline High vulnerability & 160 & 23 & 38 & 68 & 41 & 51 & 4 & 35 & 77 & 75 & 12 & 583 \\
\hline Very high vulnerability & & & & 1 & 1 & 2 & & & & 3 & & 7 \\
\hline Total & 543 & 249 & 240 & 493 & 352 & 306 & 108 & 196 & 291 & 429 & 353 & 3560 \\
\hline
\end{tabular}

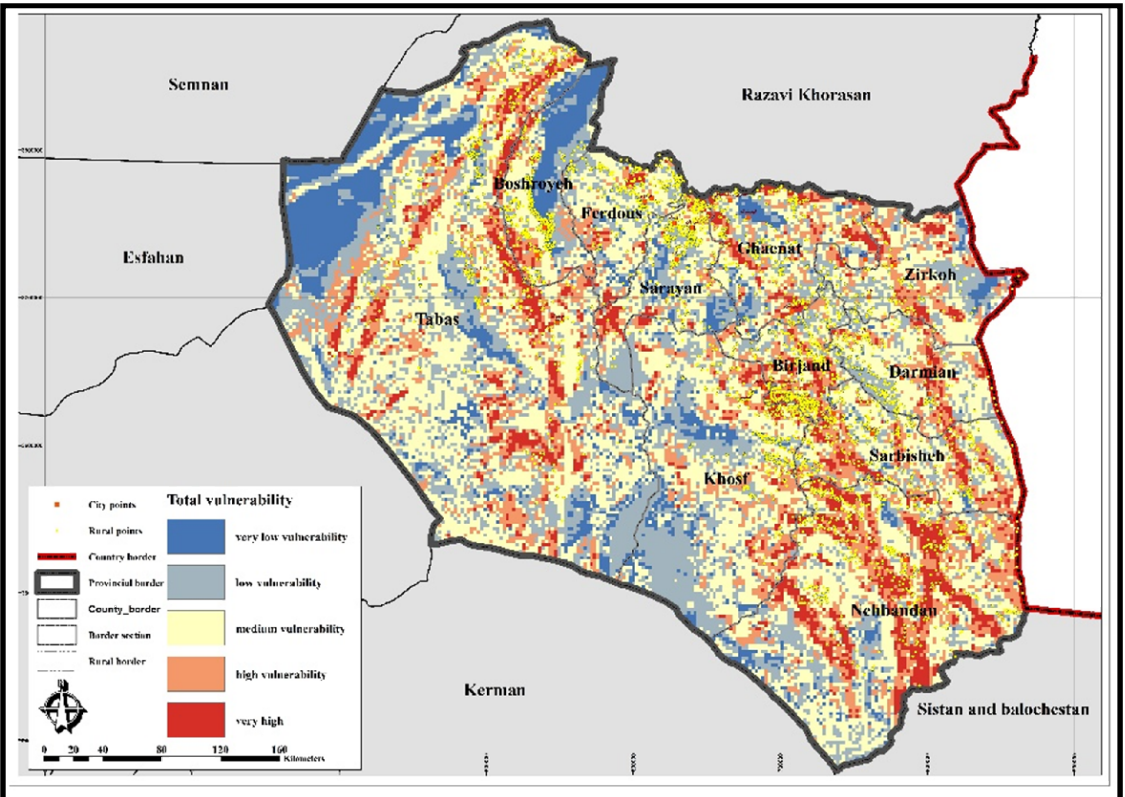

Figure 7. Integrated vulnerability zoning of the two hazards in South Khorasan province 
Table 5. Dispersion of the settlements in the vulnerability zones resulting from the integration of the two hazards under study

\begin{tabular}{|c|c|c|c|c|c|c|c|c|c|c|c|c|}
\hline Overall vulnerability & 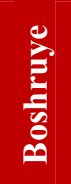 & 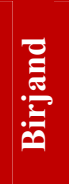 & 总 & 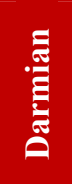 & 吾 & 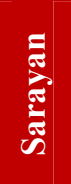 & 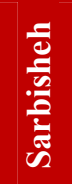 & $\frac{\text { है }}{\text { है }}$ & $\frac{8}{0}$ & 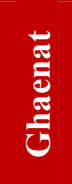 & 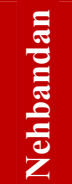 & 퐁 \\
\hline Very low vulnerability & 73 & & 8 & 12 & 3 & 13 & 7 & 20 & 16 & 7 & 7 & 166 \\
\hline Low vulnerability & 90 & 67 & 86 & 70 & 32 & 92 & 48 & 123 & 76 & 76 & 45 & 805 \\
\hline Medium vulnerability & 130 & 132 & 106 & 85 & 34 & 121 & 144 & 196 & 120 & 97 & 179 & 1344 \\
\hline High vulnerability & 49 & 136 & 60 & 25 & 30 & 48 & 96 & 86 & 10 & 30 & 152 & 722 \\
\hline Very high vulnerability & 11 & 94 & 31 & 4 & 9 & 32 & 57 & 68 & 18 & 39 & 160 & 523 \\
\hline Total & 353 & 429 & 291 & 196 & 108 & 306 & 352 & 493 & 240 & 249 & 543 & 3560 \\
\hline
\end{tabular}

the total settlements in South Khorasan province, compared to the total rural settlements. Moreover, the highest frequency of rural settlements is in the zone of moderate vulnerability so that this area with 1,344 settlements includes about $37.7 \%$ of the total settlements in the province. Table 5 summarizes the dispersion of the settlements in the vulnerability zones resulting from the integration of the two hazards under study.

\section{Discussion and Conclusion}

Iran is one of the countries with a high level of vulnerability to natural hazards. Moreover, about $7 \%$ of the total area of the country is in areas at high risk of earthquakes, and each year, floods and inundation cause a lot of damage in cities and villages. Villages are exposed to high vulnerabilities due to the type of materials, constructions, and their traditional structure. South Khorasan province with its specific geotectonic location and numerous major and minor faults has high seismic sensitivity. Furthermore, due to the specific climate of the area and the existing canals, floods occur in this province every few years, thereby leading to a lot of damage, especially in rural settlements. This study initially investigated and identified the effective indicators in the vulnerability of natural hazards (floods and earthquakes) in South Khorasan province. Hodaee and Mollashahi assessed the environmental vulnerability in Taleqan County using an analytic hierarchy process and indicated the applicability of this approach that confirms the research method used in the current study (29).

Moreover, Shamsipour et al. (2012) analyzed the environmental vulnerability in the Karaj area and indicated the fault index as the most important factor in assessing seismic vulnerability, which is consistent with the results of the present study (30). Alavi et al. (2015) investigated the spatial zone of rural settlements exposed to environmental disaster in Talesh. Moreover, using the AHP method, they determined the weight of indicators and identified areas at risk. This study also investigated and identified the villages exposed to vulnerability (31). The results of seismic vulnerability show that the range of fault expansion, especially overthrust and major faults are in the high-risk range. The dispersion of these faults can be observed frequently in the northwest and east of the province. Regarding this range, the seismic risk is high in the northwestern and eastern parts of the province; however, it is low in the southern parts of the province due to the type of faults. In addition, other areas are in the lower seismic risk range. Furthermore, based on the spatial analysis of the dispersion of settlements in vulnerable zones to earthquakes, it is observed that 214 and 502 villages are in very high and high vulnerability zones, respectively. In total, about $20 \%$ (one-fifth) of the villages in South Khorasan province are in the zone of high vulnerability to the earthquake. Moreover, the results of flood vulnerability in South Khorasan province showed that the middle, eastern, and southeastern parts are scattered and have high vulnerability around existing rivers and canals. The number of villages located in the very vulnerable zone is very limited and includes only seven villages of Chenesht, Kalateh Abbas, Takti Ti, Tangel Behdan, Ebru, Khankuk, and Ostan siah, which are located in the east of the province. The villages located in the highly vulnerable zone include about 583 villages, which accounts for $16 \%$ of the total villages in the province.

The present study can be of great help to the 
responsible organizations regarding the dispersion of rural settlements and their level of vulnerability. According to the level of vulnerability regarding the importance of immunization in villages at high risk of damage, necessary measures can be taken. Therefore, one of the most important aspects of this study is the identification of hazards and the dispersion of rural settlements in various damages. Due to the vast extension of rural settlements in South Khorasan province and crowded rural areas in the province, the constructions in these areas should not be neglected. Furthermore, due to the poverty and the condition of the underprivileged in this province, there are low-quality rural settlements that have increased their vulnerability to natural hazards. Therefore, sustainable construction in rural areas is of significant importance. Given the identification of villages at high vulnerability to hazards, the next step is to identify unsustainable housing in villages with high vulnerability to improve the sustainability and strengthen the rural fabric by those who are responsible in this regard, especially the Housing Foundation of the Islamic Revolution.

\section{Acknowledgments}

The authors would like to express their gratitude to all participants who contributed to perform this research project.

\section{Conflict of Interests}

The authors declare that there is no conflict of interest.

\section{References}

1. Faraji Mollai A, Gharkhloo M, 2010, Earthquake and Urban Crisis Management: A Case Study of Babol, Geography Quarterly 2010; 8: 143-64. (In Persian)

2. Nguyen AK, Liou YA, Li MH, Tran TA. Zoning eco-environmental vulnerability for environmental management and protection. Ecol Indic 2016; 69: 100-17.

3. Harper E. International Law and Standards Applicable in Natural Disaster Situation. Viale Vaticano. International Development Law Orga Natural Disaster; 2009.

4. Charvériat C. Natural Disasters in Latin America and the Caribbean: An Overview of Risk. New York. IDB Working Paper; 2000; 104.

5. Thomalla F, Downing T, Spanger Siegfried E, Han
G, Rockström J. Reducing hazard vulnerability: towards a common approach between disaster risk reduction and climate adaptation. Disasters. 2006; 30:39-48.

6. Eftekhari RA, Pourtaheri M, Sadeghloo T, Sojasi $\mathrm{H}$. Analyzing the affecting factors in participatory flood management in rural areas (case study: flooded villages of Gorganrood basin in Golestan province). Journal of rural Research 2011; 1:1-26. (In Persian)

7. Amiri A, Tabatabaee R. Earthquake risk management strategy plan using nonparametric estimation of hazard rate. Am J Appl Sci 2008; 5:581-5. (In Persian)

8. Moe TL, Pathranarakul P. An integrated approach to natural disaster management. Disaster Prev Manag 2006; 15:396-413.

9. Smith K. Environmental hazards: Assessing risk and reducing disaster, 3rd ed. New York. Routledge; 2001: 422.

10. Balli, S and Korukoglu, S., 2009. Operating system selection using Fuzzy AHP and TOPSIS methods. Math Comput Appl 2009; 14: 119-30.

11. Luers, A.L., 2005. The surface of vulnerability: An analytical framework for examining environmental change, Global Environmental Change 15, 214-23.

12. Tobin GA. Natural Hazards, Explanation, and Integration. In: Tobin GA, Montz BE editors. New York, London. The Guildford Press.1997

13. Bradley MP, Smith ER. Using science to assess environmental vulnerabilities. Environ Monit Assess 2004; 94:1-7.

14. Bavandpour B, Omidvar B, Salehi I. Development of Criteria for Vulnerability of Small Towns to Natural Disasters, Case Study: Gilan-e-Gharb. Journal of Urban Management 2013; 33: 19-33. (In Persian)

15. Ghadiri M. Socio-economic factors affecting the vulnerability of residential fabric in Tehran to earthquakes, Islamic Azad University, Ahar Branch, Quarterly Journal of Geographical Space 2015;15:241-62. (In Persian)

16. Alavi SA, Hosseini SM, Bahrami F, Ashorlo M. Evaluation of Urban Fabric Vulnerability Rateto Earthquake using ANP and GIS techniques (Case study: Semirom city). Scientific-Research Quarterly of Geographical Data (SEPEHR) 2017; 25:129-46. (In Persian)

17. Yari Hesar, A and Heidari Sarban, L, 2016, Evaluation of the role of development projects in reducing the vulnerability of villages to earthquakes (Case study: Varzeqan city), Quarterly Journal of Geographical Space 2016; 16:305-24. (In Persian)

18. Amiri, M, Pourghasemi, $\mathrm{H}$ and Arab-Ameri, A. Prioritizing flooding under Maharloo watersheds in Fars province using morphometric parameters and VIKOR decision model. Echo Hydrology 2018; 
5:813-27. (In Persian)

19. Araghian, E., Shokri, M. H., Flah Tabar, N. Application of fuzzy logic in the assessment and zoning of earthquake vulnerability potential (Case study: rural settlements of Tarom country). Geography 2017; 52: 343-54. (In Persian)

20. Tilahun H, Tarun Kumar R. GIS based landslide hazard evaluation and zonation - A case from Jeldu District, Central Ethiopia. J King Saud Univ Sci 2017; 29:151-65.

21. Xue L, Wang J, Zhang L, Wei G, Zhu B. Spatiotemporal analysis of ecological vulnerability and management in the Tarim River Basin, China. Sci Total Environ 2019; 649:876-88.

22. Sarvar H, Kashani Asl A. Assessment of Physical Vulnerability of Ahar City against Earthquake Crisis. Environmental based territorial planning (Amayesh) 2016; 9:87-108. (In Persian)

23. Habibi K, Poor Ahmad A, Meshkini A. Determination of structural/construction effective factors on the vulnerability of Zanjan old town texture using FUZZY LOGIC \& GIS. Honar-HaYe-Ziba 2008; 33:27-36. (In Persian)

24. Hejrati SA. Effective guideline analysis on tension management in urban development projects. Tehran city project. 2006. MSc dissertation. (In Persian)

25. Saaty TL. The analytical hierarchy process: Planning, priority setting, resource allocation. McGraw-Hill: International Book Co; 1980.

26. Saaty TL. Fundamentals of decision-making and priority theory with the analytic hierarchy process. RWS publications; 2000.

27. Gary G. An introduction to seismology. Disaster Prev Manag 1997; 6:356-61.

28. Yamani M, Tourani M, Chezghe S. Determination of the Flooding Zones by using HEC-RAS Model (Case Study: Upstream the Taleghan Dam). Journal of Geography and Environmental Hazards 2012; 1:1-6. (In Persian)

29. Shadfar S, Yamani M, Ghodousi J, Ghayoumian J. Landslide hazard zonation using analytical hierarchy method a case study; Chalakrood catchment. Watershed Management Research (pajouhesh va sazandegi) 2007; 20; 118-26. (In Persian)

30. Hodaee AA, Mollashahi M. Assessment of environmental vulnerability in Taleqan County using analytic hierarchy process. Quarterly Scientific Journal of Rescue and Relief 2016; 8:1-5. (In Persian)

31. Shamsipour AA, Feizi V, Rezaei H. Analysis of environmental vulnerability in Karaj city area used AHP. Watershed Management Research (pajouhesh- va sazandegi) 2012:91-9. (In Persian)

32. Alavi SA, Ramezannejad Y, Fattahi AA, Khalifeh E. Spatial zone of rural settlements expose to environmental disaster by using multi-criteria decision making techniques Vikor (Case study: Talesh country). Journal of Regional Planning 2016; 5:125-36 (In Persian) 